\title{
Impact of the vertical emission profiles on background gas-phase pollution simulated from the EMEP emissions over Europe
}

\author{
S. Mailler, D. Khvorostyanov, and L. Menut \\ Laboratoire de Météorologie Dynamique, UMR 8539 (École Polytechnique, École Normale Supérieure, Université Paris 6, \\ École Nationale des Ponts et Chaussées), 91128 Palaiseau Cedex, France
}

Correspondence to: S. Mailler (sylvain.mailler@1md.polytechnique.fr)

Received: 21 January 2013 - Published in Atmos. Chem. Phys. Discuss.: 8 February 2013

Revised: 19 April 201 - Accepted: 24 April 2013 - Published: 21 June 2013

\begin{abstract}
Five one-year air quality simulations over a domain covering Europe have been performed using the CHIMERE chemistry transport model and the EMEP emission dataset for Europe. These five simulations differ only by the representation of the effective emission heights for anthropogenic emissions: one has been run using the EMEP standard recommendations, three others with vertical injection profiles derived from the EMEP recommendations but multiplying the injection height by $0.75,0.50$ and 0.25 , respectively, while the last one uses vertical profiles derived from the recent literature. It is shown that using injection heights lower than the EMEP recommendations leads to significantly improved simulation of background $\mathrm{SO}_{2}, \mathrm{NO}_{2}$ and $\mathrm{O}_{3}$ concentrations when compared to the Airbase station measurements.
\end{abstract}

\section{Introduction}

Air quality modelling has emerged in recent decades as an important element in understanding and forecasting chemistry in the troposphere, particularly over highly urbanized and industrialized regions, as it is the case in Europe. While this was first performed at the urban scale, it has been shown that a proper representation of long-range transport of ozone and its precursors needs to be considered in order to have realistic modelling of air quality, even at urban scale. Therefore, Eulerian chemistry-transport models such as CHIMERE, CMAQ or CAMx, among others have been developed since the 1990s and now typically include anthropogenic emissions, biogenic emissions and advanced chem- istry such as MELCHIOR or SAPRC (Menut and Bessagnet, 2010; Zhang et al., 2012).

The three major ingredients of air quality modelling are a meteorological simulation adequately representing the state of the atmosphere in the considered region, anthropogenic and biogenic emission data for each model grid cell, and a chemistry-transport model. The model results can then be validated using ground measurements (station data, LIDAR, dropsondes) or satellite measurements (Menut and Bessagnet, 2010; Zhang et al., 2012).

Generally, anthropogenic emission data are obtained from a top-down strategy, i.e. downscaling national emission totals horizontally, vertically and in time to provide these emissions to chemistry-transport models. The horizontal disaggregation is generally realized through the use of proxies such as land use, population density or transportation networks; the temporal disaggregation follows seasonal and sub-diurnal disaggregation factors depending on the countries. The emission data used for this study are taken from the EMEP gridded emission dataset at $0.5^{\circ}$ horizontal resolution (Vestreng, 2003; Vestreng et al., 2009).

Vertical disaggregation, i.e. estimation of the effective emission heights for anthropogenic emissions, is either realized using plume-rise models such as SMOKE (Bieser et al., 2011) or tabulated factors depending on the Selected Nomenclature for Air Pollutants (SNAP) sector considered ${ }^{1}$. In the latter case, EMEP-provided disaggregation factors as provided in, e.g., Bieser et al. (2011) are the most commonly used. As noted in Bieser et al. (2011), these profiles are based on plume rise calculations for the city of Zagreb, and

\footnotetext{
${ }^{1} \mathrm{~A}$ list and description of the 10 SNAP sectors can be found, for example, in Table 1 of Bieser et al., 2011
} 
may not be representative of other European regions. Furthermore, other studies (de Meij et al., 2006; Pregger and Friedrich, 2009; Bieser et al., 2011) have questioned these results using other methodologies, obtaining effective emission heights lower than the EMEP recommendations. Pregger and Friedrich, 2009 have used data from 12699 industrial stacks in 10 German federal states, from the IER inventory, which were aggregated in 34 categories, for which relevant parameters such as weighted and unweighted average, median and standard deviation are provided for 4 main parameters: stack height, flue gas temperature, flue gas velocity and flue gas flow rate. For each of these source types, they also calculated effective emission heights assuming a standard atmosphere, finding effective emission heights significantly lower than the EMEP recommendations. Following this work and using the database provided for stack characteristics (assuming that these characteristics are relevant for all of Europe), Bieser et al. (2011) used the SMOKE-EU model to calculate 44976 vertical emission profiles for Europe depending on SNAP sector, country, climate zone, season, day and night, and pollutant type. These 44976 profiles were then reduced to 73 using cluster analysis which they use as input for the CMAQ CTM, showing that the use of these 73 profiles yielded significantly stronger $\mathrm{SO}_{2}$ and sulfate concentrations near the ground than when using the EMEP profiles. Finally, these authors provide new emission profiles following the classical EMEP layering (their Table 3). This direct comparison to the EMEP recommendations confirms the conclusions of de Meij et al. (2006) and Pregger and Friedrich (2009) regarding the fact that the latter are likely to overestimate the effective emission heights.

At global scale, Pozzer et al. (2009) have performed a sensitivity study on vertical distribution of anthropogenic emissions using the atmospheric chemistry general circulation model EMAC (ECHAM/Messy atmospheric chemistry, Jöckel et al., 2006), performing two simulations at T42 spectral resolution, corresponding to approximately $2.8^{\circ} \times 2.8^{\circ}$. The control simulation is performed by affecting the anthropogenic emissions to 6 layers between $45 \mathrm{~m}$ and $800 \mathrm{~m}$ above ground level, using fixed vertical profiles per emission class and species, and the test simulation is performed affecting all anthropogenic emissions (except aircraft emissions) to the lowest model layers. The authors show that the effect of this vertical redistribution is strong, particularly for $\mathrm{NO}_{\mathrm{x}}$, $\mathrm{CO}$, NMVOCS and $\mathrm{O}_{3}$. It is worth noting that the abovementioned study did not evaluate the impact of the vertical distribution on $\mathrm{SO}_{2}$ emissions, even though $\mathrm{SO}_{2}$ can be considered the most sensitive species to vertical emission profiles (Bieser et al., 2011). It is also worth noting that, contrary to CHIMERE, the ECHAM model includes the feedback of chemistry on meteorology through radiative processes, so that the two chemical simulations are not performed with strictly the same meteorology. These effects yield differences up to $15 \%$ in specific humidity, however, due to nudging to the ECMWF operational analysis data, the authors indicate that this impact is very weak at least for long-term averaged values.

Despite this renewed interest during recent years in the estimation of effective emission heights, to the authors' knowledge, no study has systematically investigated the impact of updating the EMEP emissions heights towards other vertical profiles in a study validated through comparison with realworld data. The purpose of the present paper is to examine several strategies for revising the EMEP vertical disaggregation, either performing manual adjustments from the EMEP profiles or vertical profiles adapted from the Bieser et al. (2011) study, and evaluate the impact of these updated vertical profiles on CHIMERE performance relative to Airbase measurements over Europe.

\section{Data and methods}

\subsection{Models and configuration}

The results presented in this version have been obtained with the CHIMERE 2011 version (Menut et al., 2013). CHIMERE is an off-line chemistry-transport model (CTM), which models atmospheric chemistry and transport, forced by anthropogenic emissions, biogenic emissions, a meteorological simulation and boundary conditions. First developed in 1997 as a box model covering the Paris area with only gasphase chemistry (Honoré and Vautard, 2000; Menut et al., 2000; Vautard et al., 2001), it is now a cartesian-mesh grid model including gas-phase, solid-phase and aqueous chemistry (Bessagnet et al., 2004), biogenic emissions modelling depending on meteorology with the MEGAN model (Guenther et al., 2006), dust emissions and resuspension (Menut et al., 2005; Vautard et al., 2005). CHIMERE has been evaluated against measurements and other CTMs both at urban scale (Vautard et al., 2007; Van Loon et al., 2007; Schaap et al., 2007) and at continental scale (Solazzo et al., 2012).

The simulation has been performed for a domain covering Europe at $0.5^{\circ}$ resolution (Fig. 1), with $79 \times 47$ horizontal grid cells. This horizontal resolution permits a representation of the large-scale circulation and main patterns of atmospheric chemistry over Europe, but does not allow for the representation of small-scale effects such as the local effect of a road, a urban area or a factory. The vertical discretization is 8 vertical levels of increasing thickness away from the ground defined in hybrid sigma-p coordinates, with the first level at 0.997 sigma-level (about $25 \mathrm{~m}$ above the ground) and the top of the last level at $500 \mathrm{hPa}$. Even though many CTM tend to work with more vertical levels, for the case of CHIMERE, the 8-level configuration is used successfully for operational forecast. A very similar configuration with 9 vertical levels has been used recently for CHIMERE in the AQMEII model intercomparison project for simulations at continental scale with a similar horizontal resolution (Solazzo et al., 2012). It has been shown recently that stepping up the number of 

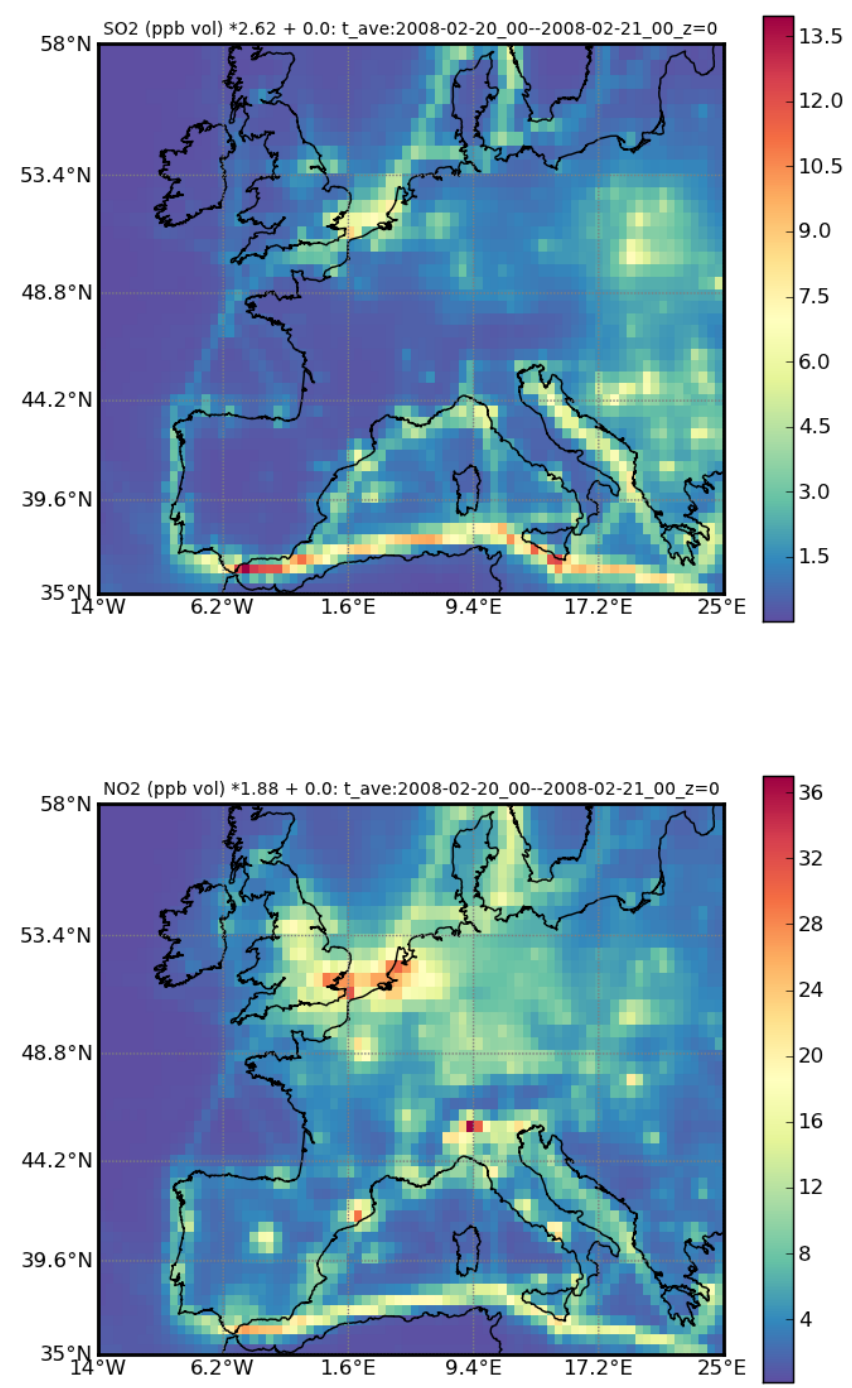

Fig. 1. (Top) average $\mathrm{SO}_{2}$ concentration simulated at the first model level in the CTL simulation $\left(\mu \mathrm{g} \mathrm{m}^{-3}\right.$ ); (bottom), same as (top) but for the $\mathrm{NO}_{2}$ concentration.

vertical levels from 8 to 20 does not measurably improve the performance of CHIMERE at least in terms of values at ground level (Menut et al., 2012).

The simulation has been initialized with LMDZ-INCA climatological data for gas species and LMDZAERO for aerosols, also used as boundary conditions, the horizontal and vertical advection has been performed using the Van Leer I scheme (Van Leer, 1979). Atmospheric chemistry has been modelled using the MELCHIOR2 scheme (Derognat et al., 2003). Biogenic emissions have been generated using the MEGAN model. All the simulations presented in this study have been performed for the period from 20 February 2008 to 19 February 2009, in order to cover a complete annual cycle.

The meteorological simulation has been performed using WRF-ARW model (Michalakes et al., 2005; Skamarock and
Klemp, 2008) version 3.2.1 on a $99 \times 99$ horizontal grid built with Lambert-conform projection with $45 \times 45 \mathrm{~km}^{2}$ horizontal resolution with a reference point at $\left(49.115^{\circ} \mathrm{N} ; 9.25^{\circ} \mathrm{E}\right)$ point, which is also the center of the domain. 27 vertical levels from 997 to $50 \mathrm{hPa}$ have been represented. The WRF options used for this study are Yonsei University planetary boundary layer, WRF single-moment 6-class microphysics, RRTM (rapid radiative transfer model) long-wave radiation, Dudhia simple downward integration short-wave radiation scheme, MM5 Monin-Obukhov similarity theory surface layer, Noah land-surface model, and the Kain-Fritsch convection scheme. The WRF model used the boundary conditions provided by the global GFS analysis fields, and no nudging was applied. The output of the meteorological simulation has thereafter been interpolated by the CHIMERE model on its own horizontal lat-lon grid and hybrid sigma-p vertical levels using the prepmet and diagmet modules. The vertical component of the wind is recalculated after the projection from the divergence of the horizontal wind field in order to secure mass conservation.

\subsection{Temporal and vertical downscaling of the emissions}

The CHIMERE horizontal grid for the simulations that have been performed correspond exactly to the grid cells for which the EMEP emissions at $0.5^{\circ} \times 0.5^{\circ}$ are provided, so that no horizontal disaggregation is needed for this study, and the emission totals per species and per SNAP sectors are used directly as provided in the EMEP database.

The vertical downscaling of the EMEP emissions for CHIMERE, which is of interest for the present study, is performed in two steps. The first step is done during the preprocessing phase of the anthropogenic emissions, where the emissions are vertically distributed into the EMEP vertical layers as defined in the standard EMEP recommendations (Table 1). As the first EMEP layer is relatively thick (92 m), and includes more than one CHIMERE layer, to avoid unnecessary vertical dilution of surface emissions between several vertical layers, the EMEP profiles have been modified in the distributed version of CHIMERE, adding a supplementary $20 \mathrm{~m}$ vertical level close to the ground. For SNAP sectors corresponding to surface emissions (SNAP 6, 7, 8, 10), $100 \%$ of the emissions are attributed to this $0-20 \mathrm{~m}$ layer; for other SNAP sectors, the 0-20 m layer receives a proportional share of the EMEP emissions from the 0-92 m layer. The temporal disaggregation of emissions from the yearly totals provided by EMEP to hourly values is also performed at this stage, using the temporal factors from the IER University of the University of Stuttgart, as done in the EMEP/MSC-W (Meteorological Synthesizing Centre-West) chemical transport model Simpson et al., 2012, as described in Menut et al., 2013. The second step of the vertical disaggregation of emissions occurs when the emission files covering the simulation period and interpolated on the model vertical grid are produced by affecting the emissions from each EMEP layer to 
the corresponding CHIMERE layer, assuming uniform vertical repartition of the emissions within each EMEP layer.

Within this preprocessing, there are mainly two possible ways to interfere with the vertical distribution of the emissions. The first way is to adapt the EMEP recommendations by lowering or raising the EMEP layers, while the other way is to conserve the standard EMEP vertical layering but change the matrix attributing the emissions to vertical layers. In the present study, both these strategies have been explored: modifying the EMEP levels (by multiplication by a factor), and redistributing the emissions between the EMEP vertical layers following the Bieser et al. (2011) recommendations and adding an additional $0-20 \mathrm{~m}$ layer in a similar way as is done usually for EMEP emissions when used in CHIMERE. The disaggregation matrix per SNAP sector and EMEP levels obtained from the Bieser et al., 2011 recommendations and from standard EMEP procedure are recapitulated in Table 1. Even though Bieser et al. (2011) provides 73 different emission profiles depending on several parameters, they show that the main dependance is on SNAP sector, while other factors such as seasonal cycle, climate zone or day/night variations have a more modest impact according to this study. Therefore, as a first step, it has been chosen to use only the average profiles for each SNAP sector as provided in Table 3 of Bieser et al. (2011).

Following these lines, 5 different simulations have been performed for the considered period:

- CTL simulation: using the standard CHIMERE configuration, i.e. vertical disaggregation from Table 1 (top)

- h75 simulation: vertical disaggregation from CTL but lowering the altitude of the EMEP levels by multiplication by 0.75 . The resulting EMEP levels are $15 \mathrm{~m}$, $138 \mathrm{~m}, 243 \mathrm{~m}, 391.5 \mathrm{~m}, 585.75 \mathrm{~m}, 829.5 \mathrm{~m}$

- h50 simulation: vertical disaggregation from CTL but lowering the altitude of the EMEP levels by multiplication by 0.5 .

- h25 simulation: vertical disaggregation from CTL but lowering the altitude of the EMEP levels by multiplication by 0.25 .

- Bie simulation: vertical disaggregation following Table 3 of Bieser et al. (2011) as presented in Table 1(bottom).

As a result of these modifications, the vertical effective emission profile for $\mathrm{SO}_{2}$ substantially differs between the five performed simulations (Table 2). The CTL emissions displays the highest effective emission heights, with the $\mathrm{h} 75$, h50 and h25 displaying decreasing emission heights compared to the CTL simulation. The simulation based on the Bieser et al. (2011) profiles is relatively close to the h50 simulation, so that it is fair to say that, regarding $\mathrm{SO}_{2}$ emissions, application of these recommendations lead to a downward

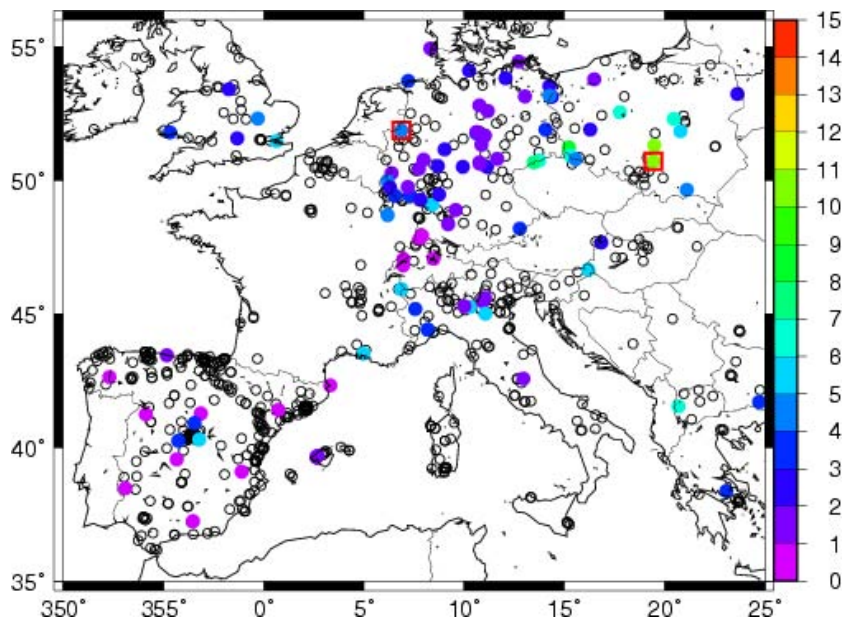

Fig. 2. Map of the 721 Airbase stations used in the study (circles), with average $\mathrm{SO}_{2}$ concentration $\left(\mu \mathrm{g} \mathrm{m}^{-3}\right)$ from Feb. 20th, 2008 to 19 February 2009) in color for the 94 stations classified as rural background. Stations DENWO81 (close to the German-Dutch border) and PL0243 (south-central Poland) studied in more detail are enclosed within a red square.

reevaluation of the $\mathrm{SO}_{2}$ effective emission heights of almost $50 \%$ at the European level, which is considerable.

\subsection{Observations and statistical methods}

The observation data were obtained from the Airbase database. A total 2266 stations had $\mathrm{NO}_{2}$ data for the covered period, 1688 had $\mathrm{O}_{3}$ data and 1459 had $\mathrm{SO}_{2}$ data. The 721 stations that have at least a $50 \%$ coverage for the given period for the three above-mentioned trace gases have been selected for comparison with simulated values, which represent a total of 721 stations covering the entire modelled area (Fig. 2). As already mentioned, due to the relatively coarse resolution of the model simulations, the model outputs can be considered as representative of background pollution levels, but not of local pollution conditions in urban and industrial areas. Therefore, the comparison of model output with observations will be possible mainly for the stations of the "rural background" type, which represent 94 out of the 721 stations selected for the simulation domain (Fig. 2).

Two criteria have been retained to compare the simulation outputs to observations. The mean bias of the model compared to the observations is calculated for each measurement station with sufficient data availability and then averaged over all stations or per station type and location. The skill score used in the present study is the same as the skill score $S$ defined by equations presented in Mao et al., 2006, which are recalled here, for a given station with $N$ time steps 
Table 1. (Top) Vertical disaggregation factors per EMEP levels (left column) and per SNAP sectors as recommended in EMEP with additional 0-20 m layer for surface emissions, as used by default in CHIMERE. (Bottom) Vertical disaggregation factors per EMEP levels (left column) and per SNAP sectors from Bieser et al. (2011), with additional 0-20 m layer for surface emissions.

\begin{tabular}{lccccccccccc}
\hline & \multicolumn{10}{c}{ SNAP sectors } \\
\cline { 2 - 11 } EMEP layers & 1 & 2 & 3 & 4 & 5 & 6 & 7 & 8 & 9 & 10 \\
\hline \multicolumn{1}{l}{ Default vertical disaggregation } \\
\hline $0-20$ & 0. & 11. & 0. & 20. & 20. & 100. & 100. & 100. & 2. & 100. \\
$20-92$ & 0. & 39. & 0. & 70. & 70. & 0. & 0. & 0. & 8. & 0. \\
$92-184$ & 0. & 50. & 4. & 10. & 10. & 0. & 0. & 0. & 15. & 0. \\
$184-324$ & 8. & 0. & 19. & 0. & 0. & 0. & 0. & 0. & 40. & 0. \\
$324-522$ & 46. & 0. & 41. & 0. & 0. & 0. & 0. & 0. & 35. & 0. \\
$522-781$ & 29. & 0. & 30. & 0. & 0. & 0. & 0. & 0. & 0. & 0. \\
$781-1106$ & 17. & 0. & 6. & 0. & 0. & 0. & 0. & 0. & 0. & 0. \\
\hline
\end{tabular}

\begin{tabular}{lcccccccccc}
\hline \multicolumn{10}{l}{ Vertical disaggregation modified after Bieser et al. (2011) } \\
\hline $0-20$ & 0. & 11. & 0. & 20. & 20. & 100. & 100. & 100. & 2. & 100. \\
$20-92$ & 0. & 89. & 21.3 & 70. & 70. & 0. & 0. & 0. & 8. & 0. \\
$92-184$ & 0.25 & 0. & 75.4 & 7. & 6. & 0. & 0. & 0. & 37. & 0. \\
$184-324$ & 51. & 0. & 3.3 & 1. & 3. & 0. & 0. & 0. & 51. & 0. \\
$324-522$ & 45.3. & 0. & 0. & 0. & 0. & 0. & 0. & 0. & 2. & 0. \\
$522-781$ & 3.29 & 0. & 0. & 0. & 0. & 0. & 0. & 0. & 0. & 0. \\
$781-1106$ & 0.2 & 0. & 0. & 0. & 0. & 0. & 0. & 0. & 0. & 0. \\
\hline
\end{tabular}

Table 2. Year-average vertical repartition of $\mathrm{SO}_{2}$ emissions (\%) for the five simulations that have been performed.

\begin{tabular}{lccccc}
\hline $\begin{array}{l}\text { Simulation } \\
\text { CHIMERE layer }\end{array}$ & CTL & Bie & h75 & h50 & h25 \\
\hline $0-25$ & 29.3 & 29.8 & 30.1 & 31.8 & 36.1 \\
$25-71$ & 4.4 & 8.4 & 5.7 & 6.4 & 8.6. \\
$71-158$ & 5.5 & 10.8 & 6.0 & 8.0 & 35.8 \\
$158-321$ & 7.7 & 26.0 & 18.2 & 34.9 & 19.5 \\
$321-532$ & 33.6 & 24.0 & 32.3 & 18.9 & 0.0 \\
$532-1240$ & 19.5 & 1.1 & 7.7 & 0.0 & 0.0 \\
$1240-2493$ & 0.1 & 0.0 & 0.0 & 0.0 & 0.0 \\
\hline
\end{tabular}

for comparison between model and observations:

$\mathrm{BIAS}=\frac{1}{N} \sum_{k=1}^{N}\left(X^{\mathrm{m}}-X^{\mathrm{o}}\right)$,

$\operatorname{ABSE}=\frac{1}{N} \sum_{k=1}^{N}\left|X^{\mathrm{m}}-X^{\mathrm{o}}\right|$,

$\operatorname{RMSE}=\left[\frac{1}{N} \sum_{k=1}^{N}\left(X^{\mathrm{m}}-X^{\mathrm{o}}\right)^{2}\right]^{\frac{1}{2}}$,

$S=\frac{1}{2}\left(1-\left|\frac{\mathrm{BIAS}}{\mathrm{ABSE}}\right|+\left|\frac{\mathrm{ABSE}}{\mathrm{RMSE}}\right|\right)$, where $X^{\mathrm{o}}$ and $X^{\mathrm{m}}$ values are the observed and modelled values, respectively. BIAS/ABSE is bounded between -1 and 1 , its target value being 0 , which indicates that there is no systematic overestimation nor underestimation by the model. ABSE/RMSE is bounded between 0 and 1 , with values close to 1 indicating that the distribution of $\left(X^{\mathrm{m}}-X^{\mathrm{o}}\right)$ has a large tail towards extreme positive or negative values. The target value for $\mathrm{S}$ is 1 , which indicates that the model is unbiased and that its errors do not display too extreme values. It is worth noting that this skill score is not sufficient to give by itself an indication of the model performance, as it does not include any evaluation of the magnitude of the model errors relative to observation - a multiplication of all the error terms $\left(X^{\mathrm{m}}-X^{\mathrm{o}}\right)$ by a constant factor will leave the skill factor $\mathrm{S}$ untouched. Therefore, in the rest of the study, the S skill factor will be used alongside the absolute value of the bias as two indicators representative of the model ability to reproduce observations.

\section{Results}

\subsection{Model results}

Figure 3 shows that the $\mathrm{SO}_{2}$ and $\mathrm{NO}_{2}$ concentrations simulated by the $\mathrm{h} 25$ simulation at the lowest model level are in excess of that simulated by the CTL simulation for all the simulated domain. This shows that the effect of injecting industrial emissions lower into the atmosphere has the effect of increasing simulated ground concentration of these primary 

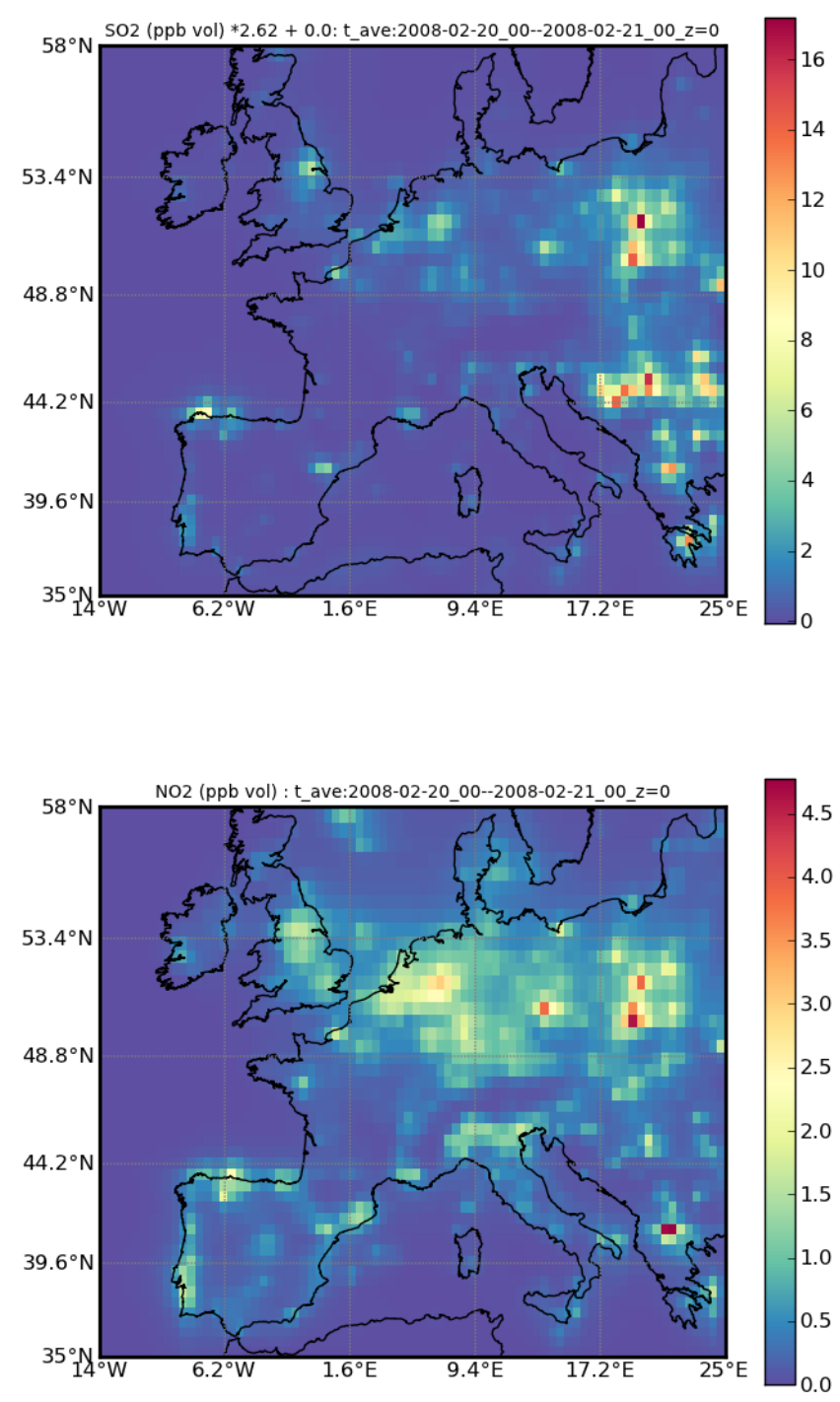

Fig. 3. (Top) Year-averaged difference between the $\mathrm{SO}_{2}$ concentration in the h25 and CTL simulation $\left(\mu \mathrm{g} \mathrm{m}^{-3}\right)$; and (bottom) same for the $\mathrm{NO}_{2}$ concentrations.

species. As it could be expected, this effect is strongest where industrial emissions are the most important, namely in all of industrial Europe, from Great Britain to Poland in Northern Europe, and for particular regions such as the Po Valley in Southern Europe. On the contrary, regions where the high $\mathrm{NO}_{2}$ and $\mathrm{SO}_{2}$ concentrations are due to sources other than stack emissions do not see a significant increase in the simulated concentrations from the CTL run to the h25 run (Fig. 1). This is for example the case of the areas of the Mediterranean Sea and North Sea that are affected by emissions related to navigation, but also of major urban areas such as Paris or London that are mostly affected by traffic and residential emissions.
Over the industrial regions, the year-average difference in $\mathrm{SO}_{2}$ concentrations reaches $16 \mu \mathrm{g} \mathrm{m}^{-3}$ for areas of Eastern Europe, which more than doubles the $\mathrm{SO}_{2}$ average concentration for these areas, reflecting the fact that the $\mathrm{SO}_{2}$ background concentrations simulated in these regions are considerably higher in the h25 simulation than in the CTL simulation. The results for $\mathrm{NO}_{2}$ are very similar, with simulated concentrations stronger in the h25 simulation than in the CTL simulation for the whole domain, with substantial differences over the major industrial regions of Europe, particularly in the eastern part of the continent.

\subsection{Comparison to observations}

\subsubsection{Statistical comparison}

The comparison of the CTL and h25 simulations to Airbase station data shows that the $\mathrm{h} 25$ simulation performs significantly better than the CTL simulation for the simulation of $\mathrm{SO}_{2}$ concentrations (Table 3), particularly for the stations categorized as "background rural" in Airbase: for these stations, the average $\mathrm{SO}_{2}$ concentration simulated by the $\mathrm{h} 25$ run is $2.7 \mu \mathrm{g} \mathrm{m}^{-3}\left(1.5 \mu \mathrm{g} \mathrm{m}^{-3}\right.$ for the CTL run, $3.0 \mu \mathrm{g} \mathrm{m}^{-3}$ for the Airbase measurements). For other types of stations, the statistical results in Table 3 confirm that, as discussed above, the horizontal resolution of the simulation outputs does not allow a realistic simulation of air quality at stations that are directly impacted by industrial, traffic or urban emissions, with a very strong underestimation of $\mathrm{SO}_{2}$ concentrations in all simulations when compared to the measured concentrations. However, the model bias and skill scores are improved for all station types in spite of the lack of representation of local phenomena, due to the improved simulation of the background levels.

For $\mathrm{NO}_{2}$, similar results are obtained when switching from the CTL to the h25 simulation, with enhanced simulation of the $\mathrm{NO}_{2}$ concentrations for the "background rural" stations $\left(10.0 \mu \mathrm{g} \mathrm{m}^{-3}\right.$ in the $\mathrm{h} 25$ simulation, against $8.4 \mu \mathrm{g} \mathrm{m}^{-3}$ for the CTL run and $10.3 \mu \mathrm{g} \mathrm{m}^{-3}$ for the Airbase measurements). For $\mathrm{O}_{3}$, all simulations exhibit excessive $\mathrm{O}_{3}$ concentrations when compared to station measurements, which is an already known characteristic of the CHIMERE model, attributed to problems in modelling $\mathrm{O}_{3}$ titration by $\mathrm{NO}$ (Solazzo et al., 2012). Due to redistribution of $\mathrm{NO}_{\mathrm{x}}$ emissions closer to the surface in the perturbed simulations, a certain degree of improvement is obtained when lowering the vertical emission profiles. For the rural background stations, the annual bias in $\mathrm{O}_{3}$ is reduced from $12.5 \mu \mathrm{g} \mathrm{m}^{-3}$ in the CTL simulation to $10.6 \mu \mathrm{g} \mathrm{m}^{-3}$ in the $\mathrm{h} 25$ simulation. For other station types, as for $\mathrm{SO}_{2}$, the simulated concentrations of $\mathrm{NO}_{2}$ and $\mathrm{O}_{3}$ are not comparable to measured concentrations due to the coarse resolution of the simulations. Generally speaking, for these stations, the $\mathrm{NO}_{2}$ concentrations are largely underestimated and the $\mathrm{O}_{3}$ concentrations are largely overestimated when compared to measurements. 
Table 3. Average $\mathrm{SO}_{2}, \mathrm{NO}_{2}$ and $\mathrm{O}_{3}$ concentrations $\left(\mu \mathrm{g} \mathrm{m}^{-3}\right.$ ) for all classes of stations for the CTL simulation (before the / character) and the h25 simulation (after the / character). In brackets is the average Airbase value for the considered category of stations. In italics are the categories that include less than 10 stations. The stations are classified according to the Airbase reported zone (Ru$\mathrm{ral} /$ Suburban/Urban/Indeterminate) and type (Background/Traffic/Industrial/Indeterminate) of the station.

\begin{tabular}{llllll}
\hline & BG & INDUS & TRAF & INDET & ALL \\
\hline $\mathrm{SO}_{2}$ & & & & \\
\hline $\mathrm{RUR}$ & $1.5 / 2.7(3.0)$ & $1.7 / 2.8(5.0)$ & $2.0 / 3.7(5.2)$ & - & $1.8 / 3.2(4.6)$ \\
$\mathrm{SUB}$ & $1.2 / 1.6(2.9)$ & $1.7 / 2.8(5.9)$ & $2.5 / 4.8(11.3)$ & - & $1.93 .3(7.3)$ \\
$\mathrm{URB}$ & - & $1.6 / 2.7(5.9)$ & $1.6 / 2.4(6.0)$ & - & $1.6 / 2.5(6.0)$ \\
$\mathrm{INDET}$ & $1.4 / 2.9(4.0)$ & $1.6 / 2.2(5.9)$ & $1.3 / 1.7(6.1)$ & $4.85 .3(4.5)$ & $1.5 / 2.3(5.4)$ \\
$\mathrm{ALL}$ & $1.4 / 2.7(3.3)$ & $1.7 / 2.6(5.5)$ & $1.8 / 3.0(5.9)$ & $4.85 .3(4.5)$ & $1.72 .9(5.3)$ \\
\hline $\mathrm{NO}_{2}$ & & & & & \\
\hline $\mathrm{RUR}$ & $8.4 / 10.0(10.3)$ & $9.3 / 10.7(23.0)$ & $10.9 / 12.8(26.6)$ & - & $9.9 / 11.6(21.4)$ \\
$\mathrm{SUB}$ & $5.5 / 6.2(12.7)$ & $7.2 / 8.4(17.1)$ & $9.5 / 11.7(24.1)$ & - & $7.7 / 9.2(18.8)$ \\
$\mathrm{URB}$ & - & $7.7 / 9.7(28.2)$ & $9.7 / 11.0(37.2)$ & - & $9.4 / 10.8(36.0)$ \\
$\mathrm{INDET}$ & $5.1 / 6.3(8.3)$ & $7.8 / 9.0(18.5)$ & $8.3 / 9.4(25.0)$ & $23.926 .2(41.1)$ & $7.3 / 8.5(17.9)$ \\
$\mathrm{ALL}$ & $7.2 / 8.6(9.8)$ & $8.4 / 9.7(21.2)$ & $10.0 / 11.6(29.6)$ & $23.926 .2(41.1)$ & $9.0 / 10.2(23.2)$ \\
\hline $\mathrm{O} \mathrm{O}_{3}$ & & & & & \\
\hline $\mathrm{RUR}$ & $73.1 / 71.2(60.6)$ & $76.6 / 74.9(49.0)$ & $70.3 / 68.2(44.9)$ & - & \\
$\mathrm{SUB}$ & $88.8 / 87.8(57.3)$ & $82.6 / 81.2(50.9)$ & $78.0 / 75.6(54.3)$ & - & $82.5 / 70.6(50.0)$ \\
$\mathrm{URB}$ & - & $81.3 / 79.2(41.3)$ & $80.9 / 79.2(41.4)$ & - & $80.9 / 79.2(41.4)$ \\
$\mathrm{INDET}$ & $86.3 / 84.6(63.4)$ & $84.7 / 83.1(53.6)$ & $82.6 / 81.0(49.1)$ & $72.970 .2(32.3)$ & $84.4 / 82.8(54.8)$ \\
$\mathrm{ALL}$ & $78.3 / 76.6(61.4)$ & $80.5 / 78.9(50.0)$ & $76.0 / 74.1(44.9)$ & $72.970 .2(32.3)$ & $77.7 / 75.9(49.7)$ \\
\hline
\end{tabular}

Therefore, as it is visible in Table 3 that, as discussed above, a meaningful comparison between CHIMERE outputs and station data in the current CHIMERE configuration is possible only for the "rural background" stations, we will examine below in more detail statistical indicators for the 94 selected "rural stations" only. For these 94 stations, a de tailed examination of the model performances relative to observations according to 4 indicators (RMSE, AMSE, MB and Mao et al., 2006 skill score) permits the drawing of several conclusions as regards the compared skill of the 5 performed simulations (Table 4).

- The CTL simulation is always the most heavily biased of the 5 simulations, for $\mathrm{O}_{3}, \mathrm{SO}_{2}$ and $\mathrm{NO}_{2}$. The concentrations of primary pollutants close to the surface tends to be systematically underestimated, and the $\mathrm{O}_{3}$ concentration overestimated. The biases are reduced when going from CTL to h75, h50 and finally h25, which is the less biased simulation for the three examined species. Due to the smaller biases in $\mathrm{h} 25$, this simulation also has the best $\mathrm{S}$ score. From this point of view, the h25 simulation can be considered as the best choice among all 5 simulations, the CTL simulation being the worst choice.
- The error indicators RMSE and ABSE are systematically stronger in the $\mathrm{h} 25$ simulation for $\mathrm{NO}_{2}$ and $\mathrm{SO}_{2}$ in spite of the lower model bias, due to stronger model variability. The other four simulations yield rather similar ABSE and RMSE values, with the best values obtained in the Bie simulation for $\mathrm{SO}_{2}$ and in the CTL and h75 simulations for $\mathrm{NO}_{2}$. This indicates that higher variability in the h25 simulation may generate larger errors than in the other, more conservative, options.

- Regarding $\mathrm{O}_{3}$, the best simulation is $\mathrm{h} 25$ for all criteria, reducing the general model bias and the errors, and increasing the skill score. This is related to the fact that the $\mathrm{h} 25$ simulation has the strongest $\mathrm{NO}_{\mathrm{x}}$ emissions in the lowest model levels, therefore increasing $\mathrm{O}_{3}$ titration and tending to reduce the traditional high-ozone bias of CHIMERE (Solazzo et al., 2012). Regarding $\mathrm{O}_{3}$, the worst simulation, with the strongest biases and errors, is the CTL simulation, followed by the $\mathrm{h} 75$ simulation, the other two simulations (h50 and Bie) behaving rather similarly, with statistical indicators closer to these of h25 than of CTL.

The examination of these statistical indicators leads to the conclusion that the CTL simulation (emissions following the standard EMEP recommendations) clearly seems to be a bad 
Table 4. RMSE, ABSE, BIAS and $\mathrm{S}$ (skill score) for $\mathrm{SO}_{2}, \mathrm{NO}_{2}$ and $\mathrm{O}_{3}$, averaged for the 94 selected rural background stations, for each of the 5 performed simulations. For each indicator, the best value(s) is (are) in bold font, the worst value(s) in italic font.

\begin{tabular}{ccccc}
\hline & RMSE & ABSE & BIAS & $\mathrm{S}$ \\
\hline $\mathrm{SO}_{2}$ & & & & \\
\hline $\mathrm{h} 25$ & 4.03 & 2.46 & $\mathbf{- 0 . 3 4}$ & $\mathbf{0 . 5 5}$ \\
$\mathrm{h} 50$ & 3.78 & 2.28 & -0.93 & $\mathbf{0 . 5 5}$ \\
$\mathrm{h} 75$ & $\mathbf{3 . 7 5}$ & 2.26 & -1.24 & 0.52 \\
$\mathrm{CTL}$ & 3.76 & 2.28 & -1.48 & 0.50 \\
$\mathrm{Bie}$ & $\mathbf{3 . 7 5}$ & $\mathbf{2 . 2 5}$ & -1.00 & 0.54 \\
\hline $\mathrm{NO}_{2}$ & & & & \\
\hline $\mathrm{h} 25$ & 10.3 & 7.17 & $\mathbf{- 0 . 2 9}$ & $\mathbf{0 . 6 2}$ \\
$\mathrm{h} 50$ & 10.1 & 6.96 & -1.12 & $\mathbf{0 . 6 2}$ \\
$\mathrm{h} 75$ & $\mathbf{1 0 . 0}$ & 6.92 & -1.55 & 0.61 \\
$\mathrm{CTL}$ & $\mathbf{1 0 . 0}$ & $\mathbf{6 . 9 1}$ & -1.88 & 0.60 \\
$\mathrm{Bie}$ & 10.1 & 6.96 & -1.11 & $\mathbf{0 . 6 2}$ \\
\hline $\mathrm{O}_{3}$ & & & & \\
\hline $\mathrm{h} 25$ & $\mathbf{2 7 . 1}$ & $\mathbf{2 1 . 8}$ & $\mathbf{1 0 . 6}$ & $\mathbf{0 . 6 4}$ \\
$\mathrm{h} 50$ & 27.2 & 22.0 & 11.4 & 0.63 \\
$\mathrm{~h} 75$ & 27.4 & 22.2 & 12.0 & 0.62 \\
$\mathrm{CTL}$ & 27.5 & 22.3 & 12.5 & 0.62 \\
$\mathrm{Bie}$ & 27.2 & 22.0 & 11.4 & 0.63 \\
\hline
\end{tabular}

choice for a wide range of criteria, while the h25 and Bie simulations clearly give the best results. The $\mathrm{h} 25$ simulation tends to reduce strongly the model biases, while generating larger errors for primary pollutants associated to larger model variability. The Bie simulation has good performances and is a more conservative choice than $\mathrm{h} 25$, with performance close to the best of the ensemble for all criteria. The good performances of the h25 simulation could perfectly be explained by error compensation between model and emission biases, leading to underestimation of the concentrations of primary pollutants and a vertical profile for anthropogenic emissions leading to emissions too close to the ground, artificially reducing model bias. This possibility is strengthened by the fact that the $\mathrm{h} 25$ simulations are based on hypotheses for the vertical emission profiles leading to emissions much closer to the ground level than the profiles provided by the Bieser et al., 2011 study, which can be considered as the actual state of the art for vertical emission profiles (Table 2). Conversely, the improvement in the Bie simulation relative to the CTL simulation can not be considered as mere error compensation between biases in the model and/or the emission dataset and a too low emission injection height, since the Bieser et al., 2011 study is based on an extensive dataset for point sources and explicit plume-rise calculations with the SMOKE-EU model and is, as far as possible in the actual state of the science, realistic. Therefore, it can be concluded from this statistical analysis that switching from the EMEP recommen- dations to the Bieser et al. (2011) profiles gives significant added value for the simulation of background atmospheric pollution over Europe, at least when the CHIMERE model is used in its present configuration.

\subsubsection{Individual stations}

Two individual stations have been selected to examine the time series of the h25, CTL and Bie simulations compared to the observations. These two particular stations have been selected because, even though they are of the "rural background" type, they display relatively high measured $\mathrm{SO}_{2}$ concentrations, due to the fact that they are in the vicinity of major industrial regions. They are therefore not necessarily representative of all the "rural background" stations, however they permit an appreciation of the effect of a modification in the effective emission heights on simulated concentration time series relative to observations for stations with significant industrial influence. DENW081 is a rural background station located in northwestern Germany, close to the border of the Netherlands. PL0243 is also a rural background station, located in southern Poland (Fig. 2). These stations are in the vicinity of the industrial regions of the Ruhr and Silesia, respectively. The simulated concentrations for $\mathrm{NO}_{2}, \mathrm{SO}_{2}$ and $\mathrm{O}_{3}$ simulated by the $\mathrm{h} 25$, Bieser and CTL simulations, as well as measured concentrations, are presented in Figs. 4 and 5. As the h50 and h75 simulations are always in-between the CTL and h25 simulation, their outputs are not presented. The first striking result here is that all three CHIMERE simulations behave similarly for the considered period and display a reasonable behaviour when compared to Airbase observations, both for DENW081 (Fig. 4) and PL0243 (Fig. 5). For both stations, as it is the case for the entire domain, the $h 25$, Bie and CTL simulations are ordered by increasing concentrations of $\mathrm{NO}_{2}$ and $\mathrm{SO}_{2}$ and decreasing $\mathrm{O}_{3}$. However, these differences have a different impact on the model's performance relative to the measurement station for these two locations.

For DENW081 (Fig. 4), all three simulations tend to slightly underestimate $\mathrm{NO}_{2}$ and $\mathrm{SO}_{2}$ peaks. The representation of the $\mathrm{O}_{3}$ maxima is good, but the diurnal cycle of $\mathrm{O}_{3}$ seems to be insufficient in this simulation, resulting in an overestimation of the average $\mathrm{O}_{3}$ concentration. The differences between the simulations are as observed for the whole set of Airbase stations, with higher $\mathrm{SO}_{2}$ concentrations in h25 during the whole period, which tends to be slightly closer to observed values when compared to the Bie simulation and the CTL simulation. $\mathrm{SO}_{2}$ peaks are also enhanced in the $\mathrm{h} 25$ simulation and also, to a lesser extent, in the Bieser simulation, when compared to the Bieser simulation. $\mathrm{O}_{3}$ differences between the three simulations are moderate, but quite measurable at night, where the nocturnal $\mathrm{O}_{3}$ minimum values are more realistic in the $\mathrm{h} 25$ simulation than in the CTL or Bie simulations, particularly for periods with high $\mathrm{NO}_{2}$ concentrations, when the $\mathrm{NO}_{2}$ peaks and corresponding $\mathrm{O}_{3}$ minima 

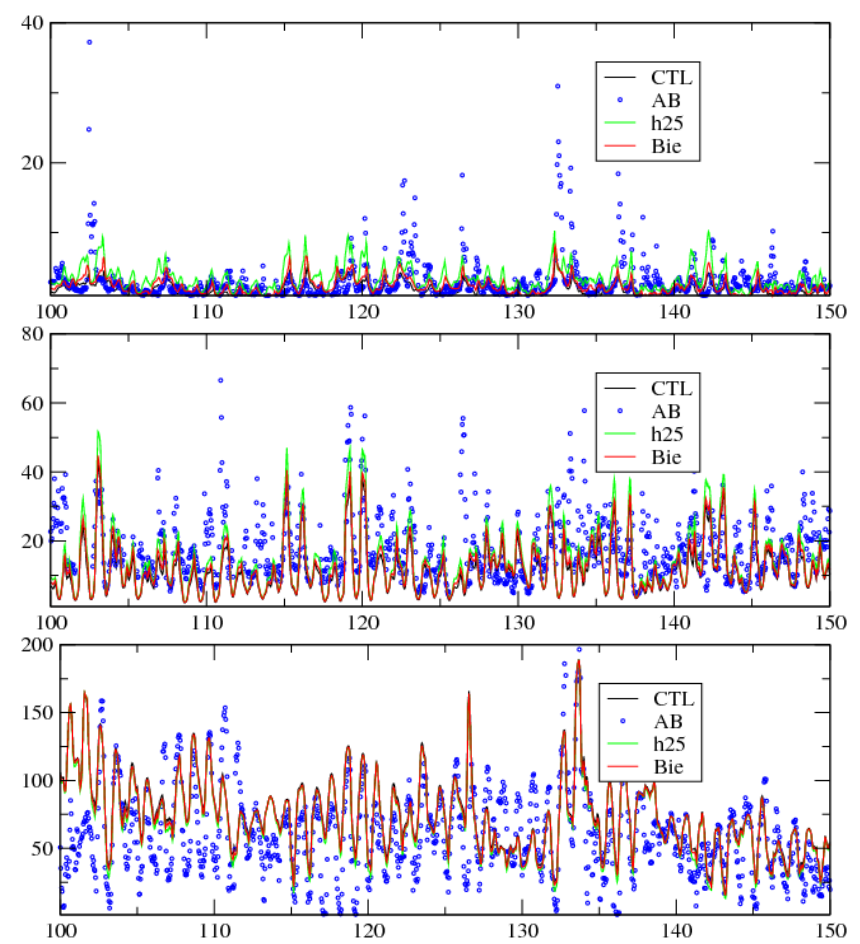

Fig. 4. Time series for Airbase station DENW081 (Borken-Gemen, $51.86 \mathrm{~N}-6.87 \mathrm{E}$ ), rural station in North Rhine-Westphalia, from 29 May 2008 to 18 July 2008. Time is in days from the start of the simulation, time series for $\mathrm{SO}_{2}$ (above), $\mathrm{NO}_{2}$ (middle) and $\mathrm{O}_{3}$ (below) are presented, in $\mu \mathrm{g} \mathrm{m}^{-3}$.

are represented better in the CTL simulation (see day 103 for example). The representation of $\mathrm{O}_{3}$ maxima is rather good in all three simulations, and not considerably altered by the change in the vertical distribution of the emissions. All in all, for this particular station, the $\mathrm{h} 25$ simulation gives better results than the Bie simulation, which itself gives better results than the CTL simulation. The reduction in average $\mathrm{O}_{3}$ concentrations is essentially due to $\mathrm{O}_{3}$ titration at night by primary contaminants and does not necessarily imply a diminution of the daily maxima.

For PL0243 (Fig. 5), the $\mathrm{SO}_{2}$ concentrations are either overestimated or underestimated by all three simulations simultaneously, with the differences reaching $80 \mu \mathrm{g} \mathrm{m}^{-3}$ between the CTL and the $\mathrm{h} 25$ simulation, $30 \mu \mathrm{g} \mathrm{m}{ }^{-3}$ between the CTL and Bie simulation. Some peaks are adequately catched by the model, particularly in the Bieser simulation (days 315 and 325) or the h25 simulation (days 329-330). Generally, every time that a peak simulated in CHIMERE coincides with an observed peak, the peak is underestimated in the CTL simulation, which is not the case in the $\mathrm{h} 25$ or Bie simulations. Regarding $\mathrm{NO}_{2}$, for this station, CHIMERE tends to overestimate the $\mathrm{NO}_{2}$ concentrations for the considered period. This overestimation is weakest in the CTL simulation and strongest in the $\mathrm{h} 25$ simulation, even though
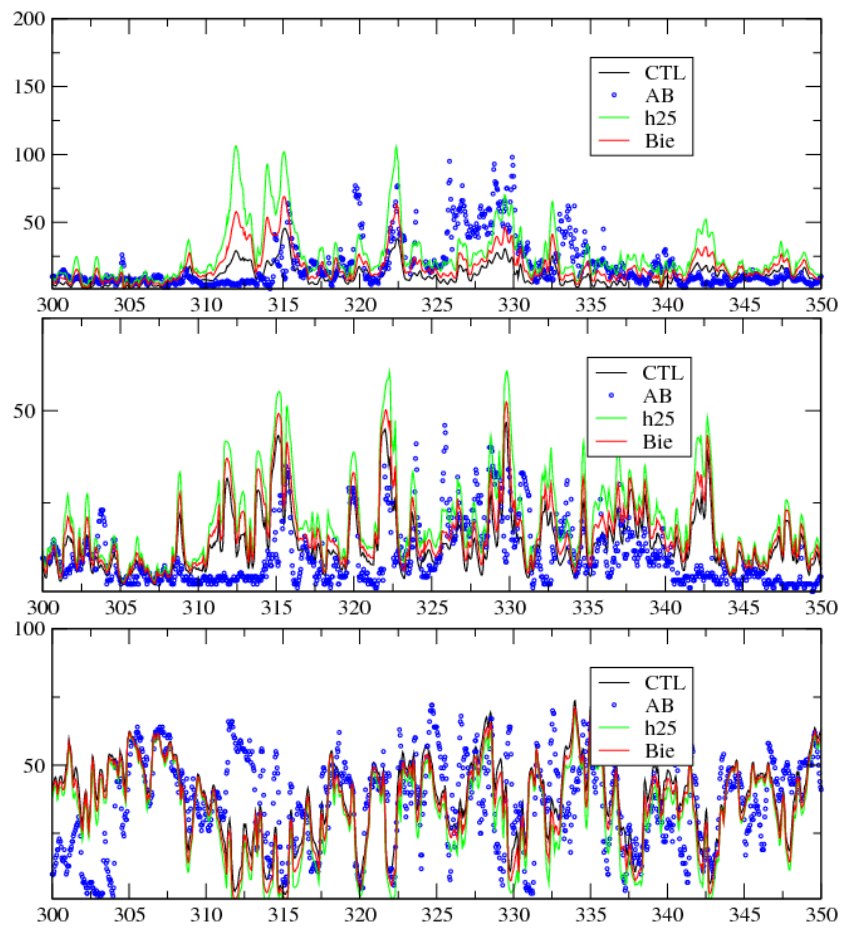

Fig. 5. Time series for Airbase station PL0243 (Potok-Zloty, $50.71^{\circ} \mathrm{N}-19.46^{\circ} \mathrm{E}$ ), rural station in Lower Silesia (Poland), from 15 December 2008 to 3 February 2009. Time is in days from the start of the simulation, time series for $\mathrm{SO}_{2}$ (above), $\mathrm{NO}_{2}$ (middle) and $\mathrm{O}_{3}$ (below) are presented, in $\mu \mathrm{g} \mathrm{m}^{-3}$.

the quantitative differences between these three simulations are not as strong as in the case of $\mathrm{SO}_{2}$. In spite of this general overestimation, the agreement between simulated and measured $\mathrm{NO}_{2}$ is globally good for this period, even though two significant peaks are simulated and not observed (around day 312 and day 342-343). A period of generally high $\mathrm{NO}_{2}$ concentrations between day 325 and day 340 is adequately represented in all three simulations. However, for the whole considered period, $\mathrm{NO}_{2}$ concentrations are slightly overestimated in all three simulations, more particularly in the Bie and h25 simulations. Regarding the $\mathrm{O}_{3}$ concentrations, their representation is good in all three simulations, and both $\mathrm{O}_{3}$ peaks and minima tend to be represented correctly. As could be expected, the higher $\mathrm{NO}_{2}$ concentrations in the $\mathrm{h} 25$ and Bie runs are associated to more pronounced $\mathrm{O}_{3}$ minima. Compared to the DENW081 station, the more realistic representation of $\mathrm{NO}_{2}$ concentration and $\mathrm{O}_{3}$ concentration minima relative to Airbase seems to indicate a better representation of the NO-NO${ }_{2}-\mathrm{O}_{3}$ cycle for this grid cell, either due to better emissions or to the meteorological conditions. It is also arguable that the $\mathrm{NO}_{2}$ concentrations measured in DENW08 are not representative of the entire grid cell, since the DENW081 Airbase station is located in the 
town of Borken (Germany), with possible local traffic effects, unlike Potok Zloty (Poland) which is just a village.

\section{Discussion and conclusions}

Five air quality simulations were performed with CHIMERE from 20 February 2008 to 19 February 2009 for a domain covering Europe at $0.5^{\circ}$ horizontal resolution, with a meteorological simulation from WRF and anthropogenic emissions from the EMEP database at $0.5^{\circ}$ resolution. These five simulations have been conducted using either the EMEP recommendations for vertical disaggregation (CTL simulation), modifying them by a factor of $0.25,0.50$ and $0.75(\mathrm{~h} 25, \mathrm{~h} 50$ and h75 simulations, respectively), or using the alternative profiles of Bieser et al. (2011) (Bie simulation). The vertical emission profiles were the only difference between these 5 simulations, which have been performed using the same meteorology, the same horizontal and temporal repartition of the emissions, and the same CTM with the same configuration. Therefore, their results could be analyzed directly in terms of the impact of vertical disaggregation factors on simulated pollutant concentrations.

Due to the relatively coarse model resolution, the model results are representative only of the concentrations measured by the rural background stations, so that the simulations outputs have been compared mainly to measurements from the 94 "rural background" Airbase measurement stations within the simulation domain that had sufficient data availability during the considered period. For these 94 stations, the use of the Bieser et al. (2011) profiles permits a reduction of the model bias of respectively $32 \%, 59 \%$ and $9 \%$ for $\mathrm{SO}_{2}, \mathrm{NO}_{2}$ and $\mathrm{O}_{3}$ (Table 4), so that in the case of $\mathrm{SO}_{2}$ and $\mathrm{NO}_{2}$, the errors on the simulated background concentrations due to the uncertainties on the effective emission heights have the same order of magnitude than the biases of the simulated concentrations relative to ground measurements: improving the evaluation of the effective emission height is a key factor in improving the representation of the background atmospheric composition. The interpretation of the large bias reduction obtained when reducing the effective emission heights for stack emissions from the standard EMEP recommendations to the Bieser et al. (2011) recommendations is the same for $\mathrm{SO}_{2}$ and $\mathrm{NO}_{2}$, which are primary pollutants. For these pollutants, the reduction in the model underprediction can be directly attributed to the fact that industrial $\mathrm{NO}_{2}$ and $\mathrm{SO}_{2}$ is emitted at lower model levels in the the Bie simulation than in the CTL simulation. For $\mathrm{O}_{3}$, which is not a primary pollutant, the reduction in CHIMERE overprediction is a consequence of stronger simulated $\mathrm{NO}_{\mathrm{x}}$ concentrations in the lowest atmospheric layers, leading to stronger nighttime $\mathrm{O}_{3}$ titration by NO. The $\mathrm{h} 25$ simulation, which uses vertical profiles leading to emissions lower into the atmosphere than the Bieser et al. (2011) profiles leads to even stronger reduction of the model biases compared to the CTL simulations (respectively $77 \%, 85 \%$ and $15 \%$ for $\mathrm{SO}_{2}, \mathrm{NO}_{2}$ and $\mathrm{O}_{3}$ ), but this stronger reduction could very well be due to compensation of biases in the model and/or total emissions by the use of artificially low effective emission heights. The h75 and h50 simulations display characteristics that are intermediate between $\mathrm{h} 25$ and CTL, in both cases clearly improving the CTL simulation relative to Airbase measurements. Comparison to station data shows that the impact of the different vertical emission profiles on $\mathrm{NO}_{2}$ and $\mathrm{SO}_{2}$ concentrations can affect the simulated $\mathrm{SO}_{2}$ concentrations by a factor 2 , including for peak values, and even for rural background stations, so that the impact of vertical emission profiles on the modelling of $\mathrm{SO}_{2}$ is fundamental, and much attention should be devoted to this problem. For $\mathrm{NO}_{2}$, the impact is quite significant too, with the use of the $\mathrm{h} 25$ or Bieser vertical profiles contributing to reducing the low bias of CHIMERE simulated $\mathrm{NO}_{2}$ concentrations for stations where CHIMERE exhibits this low bias, which is the case with most stations. In such cases, as for the DENW081 Airbase station, lowering the vertical emission profiles has the effect of reducing the bias and therefore indirectly improving the simulation of $\mathrm{O}_{3}$ concentrations, particularly nighttime $\mathrm{O}_{3}$ titration.

These results show that, due to very large uncertainties in its computation, vertical disaggregation can be a major error cause in air quality modelling, particularly in the regions influenced by large stack emissions such as large parts of Eastern Europe and the most industrial parts of western and southern Europe. Overestimation of effective emission heights, as seems to be the case of the EMEP recommendations, is a determinant contribution to $\mathrm{NO}_{2}$ and $\mathrm{SO}_{2}$ underestimation in CHIMERE when using the EMEP emission dataset, and to $\mathrm{O}_{3}$ overestimation, particularly during nighttime. These biases can be corrected in a relatively straightforward way by applying alternative vertical emission profiles that lead to lower effective emission altitude, such as the ones proposed by Bieser et al. (2011). Therefore, the use of the Bieser et al. (2011) profiles will be proposed in future versions of CHIMERE, which should be a way of generally improving the simulated concentrations of primary and secondary contaminants of anthropic origin. As this study has been performed with only one model, CHIMERE in its 2011 version, and one horizontal $\left(0.5^{\circ} \times 0.5^{\circ}\right)$ and vertical $(8 \mathrm{lev}-$ els from 0.997 sigma-level to $500 \mathrm{hPa}$ ) discretization, its results might not be directly applicable to other CTMs or other vertical resolutions.

The authors think that these questions should receive increased attention in the following years, due to their strong impact on the simulated concentrations of all chemical species influenced by industrial activities. As shown here for CHIMERE, a reevaluation of the vertical emission heights using state-of-the-art vertical profiles, instead of profiles that had been provided using earlier methodologies, might bring significant added value to the simulated concentrations for other CTMs as well. 
Acknowledgements. The authors are grateful to the two anonymous revewers as well as to the Editor for their useful remarks that helped to improve greatly the initial manuscript. We also wish to acknowledge Bertrand Bessagnet for useful discussions during the preparation of this article. Data from the Airbase database is kindly provided by the European Environmental Agency.

Edited by: A. Pozzer

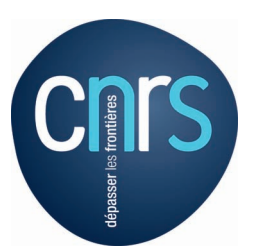

The publication of this article is financed by CNRS-INSU.

\section{References}

Bessagnet, B., Hodzic, A., Vautard, R., Beekmann, M., Cheinet, S., Honoré, C., Liousse, C., and Rouil, L.: Aerosol modeling with CHIMERE: preliminary evaluation at the continental scale, Atmos. Environ., 38, 2803-2817, 2004.

Bieser, J., Aulinger, A., Matthias, V., Quante, M., and Denier van der Gon, H.: Vertical emission profiles for Europe based on plume rise calculations., Environ. Pollut., 159, 2935-2946, doi:10.1016/j.envpol.2011.04.030, 2011.

de Meij, A., Krol, M., Dentener, F., Vignati, E., Cuvelier, C., and Thunis, P.: The sensitivity of aerosol in Europe to two different emission inventories and temporal distribution of emissions, Atmos. Chem. Phys., 6, 4287-4309, doi:10.5194/acp-6-4287-2006, 2006.

Derognat, C., Beekmann, M., Baeumle, M., Martin, D., and Schmidt, H.: Effect of biogenic volatile organic compound emissions on tropospheric chemistry during the Atmospheric Pollution Over the Paris Area(ESQUIF) campaign in the Ile-de-France region, J. Geophys. Res., 108, 8560, 2003.

Guenther, A., Karl, T., Harley, P., Wiedinmyer, C., Palmer, P. I., and Geron, C.: Estimates of global terrestrial isoprene emissions using MEGAN (Model of Emissions of Gases and Aerosols from Nature), Atmos. Chem. Phys., 6, 3181-3210, doi:10.5194/acp-63181-2006, 2006.

Honoré, C. and Vautard, R.: Photochemical regimes in urban atmospheres: The influence of dispersion, Geophys. Res. Lett., 27, 1895-1898, 2000.

Jöckel, P., Tost, H., Pozzer, A., Brühl, C., Buchholz, J., Ganzeveld, L., Hoor, P., Kerkweg, A., Lawrence, M. G., Sander, R., Steil, B., Stiller, G., Tanarhte, M., Taraborrelli, D., van Aardenne, J., and Lelieveld, J.: The atmospheric chemistry general circulation model ECHAM5/MESSy1: consistent simulation of ozone from the surface to the mesosphere, Atmos. Chem. Phys., 6, 50675104, doi:10.5194/acp-6-5067-2006, 2006.

Mao, Q., Gautney, L. L., Cook, T. M., Jacobs, M. E., Smith, S. N., and Kelsoe, J. J.: Numerical experiments on MM5-CMAQ sensitivity to various PBL schemes, Atmos. Environ., 40, 3092-3110, 2006.

Menut, L. and Bessagnet, B.: Atmospheric composition forecasting in Europe., Annals Geophys., 28, 61-74, 2010.

Menut, L., Vautard, R., Beekmann, M., and Honoré, C.: Sensitivity of Photochemical Pollution using the Adjoint of a Simpli- fied Chemistry-Transport Model, J. Geophys. Res., 105, 15379 15402, 2000.

Menut, L., C.Schmechtig, and B.Marticorena: Sensitivity of the sandblasting fluxes calculations to the soil size distribution accuracy, J. Atmos. Ocean. Tech., 22, 1875-1884, 2005.

Menut, L., Bessagnet, B., Colette, A., and Khvorostiyanov, D.: On the impact of the vertical resolution on chemistry transport modelling, Atmos. Environ., 67, 370-384, 2012.

Menut, L., Bessagnet, B., Khvorostyanov, D., Beekman, M., Colette, A., Coll, I., Curci, G., Foret, G., Hodzic, A., Mailler, S., Meleux, F., Monge, J.-L., Pison, I., Turquety, S., Valari, M., Vautard, R., and Vivanco, M. G.: Regional atmospheric composition modeling with CHIMERE version 2011, Geosci. Model Dev. Discuss., accepted, 2013.

Menut, L., Bessagnet, B., Khvorostyanov, D., Beekmann, M., Colette, A., Coll, I., Curci, G., Foret, G., Hodzic, A., Mailler, S., Meleux, F., Monge, J.-L., Pison, I., Turquety, S., Valari, M., Vautard, R., and Vivanco, M. G.: Regional atmospheric composition modeling with CHIMERE, Geosci. Model Dev. Discuss., 6, 203 329, doi:10.5194/gmdd-6-203-2013, 2013.

Michalakes, J., Dudhia, J., Gill, D., Henderson, T., Klemp, J., Skamarock, W., and Wang, W.: The Weather Research and Forecast Model: Software Architecture and Performance, To appear in proceeding of the Eleventh ECMWF Workshop on the Use of High Performance Computing in Meteorology, 25-29 October 2004, Reading, U.K., Ed. George Mozdzynski, 2004.

Pozzer, A., Jöckel, P., and Van Aardenne, J.: The influence of the vertical distribution of emissions on tropospheric chemistry, Atmos. Chem. Phys., 9, 9417-9432, doi:10.5194/acp-9-9417-2009, 2009.

Pregger, T. and Friedrich, R.: Effective pollutant emission heights for atmospheric transport modelling based on real-world information, Environ. Pollut., 157, 552-560, 2009.

Schaap, M., Vautard, R., Bergstrom, R., van Loon, M., Bessagnet, B., Brandt, J., Christensen, H., Cuvelier, K., Foltescu, V., Graff, A., E., J. J., Kerschbaumer, A., Krol, M., Langner, J., Roberts, P., Rouil, L., Stern, R., Tarrason, L., Thunis, P., Vignati, E., White, L., Wind, P., and Builtjes, P. H. J.: Evaluation of long-term aerosol simulations from seven air quality models and their ensemble in the EURODELTA study, Atmos. Environ., 41, 2083-2097, 2007.

Simpson, D., Benedictow, A., Berge, H., Bergström, R., Emberson, L. D., Fagerli, H., Flechard, C. R., Hayman, G. D., Gauss, M., Jonson, J. E., Jenkin, M. E., Nyiri, A., Richter, C., Semeena, V. S., Tsyro, S., Tuovinen, J.-P., Valdebenito, A., and Wind, P.: The EMEP MSC-W chemical transport model - technical description, Atmos. Chem. Phys., 12, 7825-7865, doi:10.5194/acp12-7825-2012, 2012.

Skamarock, W. and Klemp, J.: A time-split nonhydrostatic atmospheric model for weather research and forecasting applications., J. Comput. Phys., 227, 3465-3485, doi:10.1016/j.jcp.2007.01.037, 2008.

Solazzo, E., Bianconi, R., Vautard, R., Appel, K. W., Moran, M. D., Hogrefe, C., Bessagnet, B., Brandt, J., Christensen, J. H., Chemel, C., Coll, I., van der Gon, H. D., Ferreira, J., Forkel, R., Francis, X. V., Grell, G., Grossi, P., Hansen, A. B., Jeričević, A., Kraljević, L., Miranda, A. I., Nopmongcol, U., Pirovano, G., Prank, M., Riccio, A., Sartelet, K. N., Schaap, M., Silver, J. D., Sokhi, R. S., Vira, J., Werhahn, J., Wolke, R., Yarwood, 
G., Zhang, J., Rao, S., and Galmarini, S.: Model evaluation and ensemble modelling of surface-level ozone in Europe and North America in the context of AQMEII, Atmos. Environ., 53, 60-74, doi:10.1016/j.atmosenv.2012.01.003, 2012.

Van Leer, B.: Towards the ultimate conservative difference scheme. V A second order sequel to Godunov's method, J. Computational Phys., 32, 101-136, 1979.

Van Loon, M., Vautard, R., Schaap, M., Bergstrom, R., Bessagnet, B., Brandt, J., Builtjes, P., Christensen, J. H., Cuvelier, K., Graf, A., Jonson, J., Krol, M., Langner, J., Roberts, P., Rouil, L., Stern, R., Tarrason, L., Thunis, P., Vignati, E., White, L., and Wind, P.: Evaluation of long-term ozone simulations from seven regional air quality models and their ensemble average, Atmos. Environ., 41, 2083-2097, 2007.

Vautard, R., Beekmann, M., Roux, J., and Gombert, D.: Validation of a hybrid forecasting system for the ozone concentrations over the Paris area, Atmos. Environ., 35, 2449-2461, 2001.
Vautard, R., Bessagnet, B., Chin, M., and Menut, L.: On the contribution of natural Aeolian sources to particulate matter concentrations in Europe: testing hypotheses with a modelling approach, Atmos. Environ., 39, 3291-3303, 2005.

Vautard, R., Builtjes, P. H. J., Thunis, P., Cuvelier, K., Bedogni, M., Bessagnet, B., Honoré C., Moussiopoulos, N., G., P., Schaap, M., Stern, R., Tarrason, L., and Van Loon, M.: Evaluation and intercomparison of Ozone and PM10 simulations by several chemistry-transport models over 4 European cities within the City-Delta project, Atmos. Environ., 41, 173-188, 2007.

Vestreng, V.: Review and revision of emission data reported to CLRTAP, Tech. rep., EMEP, Oslo, Norway, 2003.

Vestreng, V., Ntziachristos, L., Semb, A., Reis, S., Isaksen, I. S. A., and Tarrasón, L.: Evolution of $\mathrm{NO}_{\mathrm{x}}$ emissions in Europe with focus on road transport control measures, Atmos. Chem. Phys., 9, 1503-1520, doi:10.5194/acp-9-1503-2009, 2009.

Zhang, Y., Bocquet, M., Mallet, V., Seigneur, C., and Baklanov, A.: Real-time air quality forecasting, part I: History, techniques, and current status, Atmos. Environ., 60, 632-655, 2012. 